\title{
EU28 Countries Performance in eGovernment in 2019-2020
}

\author{
Victor Marian DUMITRACHE \\ Marian NĂSTASE ${ }^{2}$ \\ Valentin LAZĂR \\ Cosmin ANDREICA ${ }^{4}$ \\ Petrut Cristian VASILACHE
}

\begin{abstract}
The shift from traditional to digital delivery of public services is a complicated process in which governments must balance the cost effectiveness and nondiscriminatory access to public services. This shift requires a deep understanding of the factors that may influence the digital delivery of public services and a strategy for making the change possible.

The purpose of this paper is to point out the major differences between EU countries in terms of eGovernment performance.

We will perform a comparative analysis among EU28 countries based on the indicators aggregated under eGovernment indicators group of the Digital Economy and Society Index.

This paper provides a general analysis of the development of digital public services in the EU countries. Based on this analysis, public administration registering the lowest scores (i) can identify the best practices sources by looking at the countries with the highest scores, and (ii) can perform in depth research to identify the root causes of digital channels poor performance and improve them through custom-made interventions.
\end{abstract}

Keywords: digital, public services, eGovernment, public authorities

JEL classification: $\mathrm{H} 11, \mathrm{H} 80$

DOI: $10.24818 /$ RMCI.2021.1.102

\section{Introduction}

One of the main challenges in public administration and management in the last two decades has been the digitalization of public services. Nowadays, some EU countries prove to have a high level of digitalization of public services, while

\footnotetext{
${ }^{1}$ Victor Marian Dumitrache, Bucharest University of Economic Studies, E-mail: victor.dumitrache@gmail.com

${ }^{2}$ Marian Năstase, Bucharest University of Economic Studies, E-mail: nastasemarian@yahoo.com

${ }^{3}$ Valentin Lazăr, Bucharest University of Economic Studies, E-mail: valentin.lazar@ase.ro

${ }^{4}$ Cosmin Andreica, University Bucharest, E-mail: cosminandreica@yahoo.com

${ }^{5}$ Petruț Cristian VASILACHE, Bucharest University of Economic Studies, vasilachepetrutcristian@yahoo.com
} 
others still relay on the traditional delivery (Faulkner et al, 2019). Moreover, even in highly digitalized public administrations, most of the public services are delivered both traditionally and through digital channels (Anthopoulos et al, 2016) which is not cost effective in some circumstances.

Some governments already apply a systematic approach - Multi-Channel Management Strategy - making mandatory the delivery of public services only through online channels, like Denmark (Madsen et al, 2016) and the Netherlands (Pieterson, 2010).

Research has shown that the transition from traditional to digital delivery of public services is influenced by several factors like:

- the ambiguity and complexity of the tasks. Ebbers (et al, 2016) proved that for public services that require complex and ambiguous tasks, the citizens prefer channels that offer them high communication richness (e.g. face-to-face).

- the level of cognitive effort required to access a public service. Faulkner (et al, 2019) showed that when having to choose from traditional and digital delivery, citizens prefer the channel that requires the least cognitive effort.

- the level of digital skills and bureaucratic competences (Ebbers et al, 2016) that influence the way a citizen perceive, on one hand, the complexity and ambiguity of a task and, on the other hand, the communication richness that a digital channel of delivery may offer (Ebbers et al, 2018);

Especially in countries or sectors where the citizens do not have the proper level of digital skills, shifting from traditional to digital public services is complicated. A public service must be delivered to all citizens without discrimination and respecting the budgetary constraints. (Pieterson, 2010)

So far, several types of interventions have been developed to foster digital public services delivery:

- Behavioral intervention - Users will change their behavior towards the digital channel because: (i) they are not aware of having any other option and (ii) the digital delivery seems to be the option with the highest pay-off in the short term, while no mental additional effort is required. (Faulkner, 2019)

- Channel management interventions. Pieterson (2010) presented several options: (i) Parallel positioning: public services are available both in digital and traditional delivery setting. (ii) Replacement positioning: digital channels replace the traditional channels. (iii) Supplemental positioning: each service is delivered through the best channel relative to the tasks. (iv) Integrated positioning: services are available through 
all channels, but the way they are integrated guide users towards the "best" option - usually to the digital delivery.

- Mandatory setting. Madsen (et al, 2015) showed that citizens can be conditioned to use mandatory digital channels for public services delivery through (i) third party channels, like online banking and search engines and (ii) the presence of multiple digital and traditional (like phone-based) communication channels that support the digital delivery.

Any public administration can shift from traditional to digital delivery of public services as long as it understands the factors that may encourage and discourage citizens to use digital channels and as long as it designs interventions adapted to the factors of influence.

This paper provides a general analysis of the development of digital public services in the EU countries. Based on this analysis, public administration registering the lowest scores (i) can identify the best practices sources by looking at the countries with the highest scores, and (ii) can perform in depth research to identify the root causes of digital channels poor performance and improve them through custom-made interventions.

\section{Methodology}

The current analysis is done at the level of EU28 counties. It is based on Digital Economy and Society Index 2020 (DESI 2020) raw data. This data is available at https://digital-agenda-data.eu/datasets/desi/visualizations. The charts were generated by the authors making use of the advanced data visualization tool from the platform.

Considering the purpose of this analysis:

- For the indicators that refer to individuals, we chose the age group (25-54) that is the most active in society and economy and which also has a predictable behavior that is hard to change.

- we selected four indicators aggregated under eGovernment dimension of DESI, based on which we compared the EU28 countries: 1) Individuals interacting online with public authorities in 2020; 2) Individuals submitting completed forms to public authorities, over the internet in 2020; (3) Online service completion in 2019; (4) Digital public services for business in 2019 


\section{Results and discussion}

Individuals interacting online with public authorities, last 12 months, Individuals, 25 to 54 years old

Year:2020

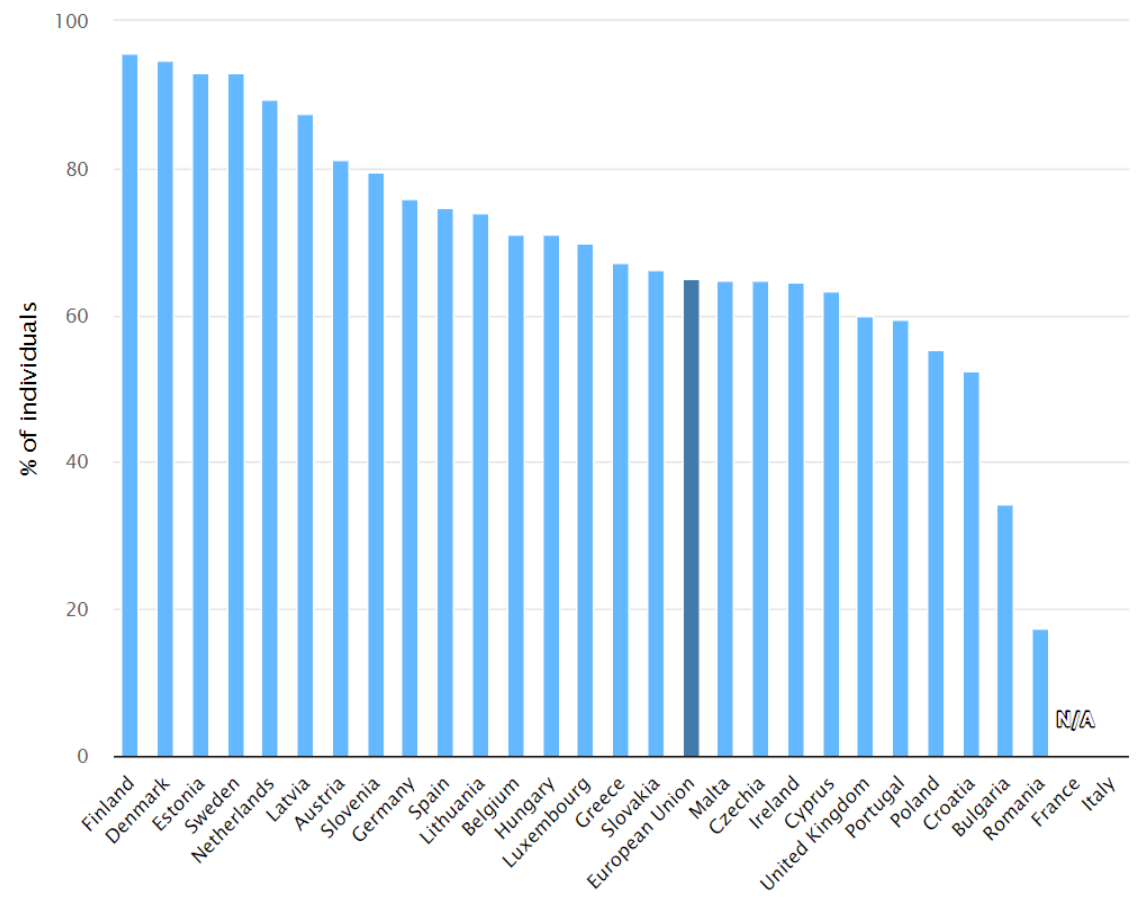

Chart 1: Individuals interacting online with public authorities

Chart 1 presents the percentage of individuals aged 25 to 54 who have interacted online with a public authority in the past 12 months. The interaction may refer at least to obtaining information from the public authorities' websites, but it may also refer to direct interactions with public authorities in the online environment like downloading official forms or sending filled in forms.

As we can see in Chart 1, the EU countries with the highest percentage of individuals interacting online with public authorities are Finland (95.7\%), Denmark (94.6\%), Estonia (93.1\%) and Sweden (93\%). The countries with the lowest percentages of individuals interacting online with public authorities are Bulgaria (34.4\%) and Romania (17.4\%) - no data available for France and Italy. This poor performance may be influenced either by the lack of digital public services or by the lack of digital skills among population - skills that would enable them to access the online public services or at least information about them. 
Individuals submitting completed forms to public authorities, over the internet,

last 12 months, Individuals, 25 to 54 years old

Year:2020

100

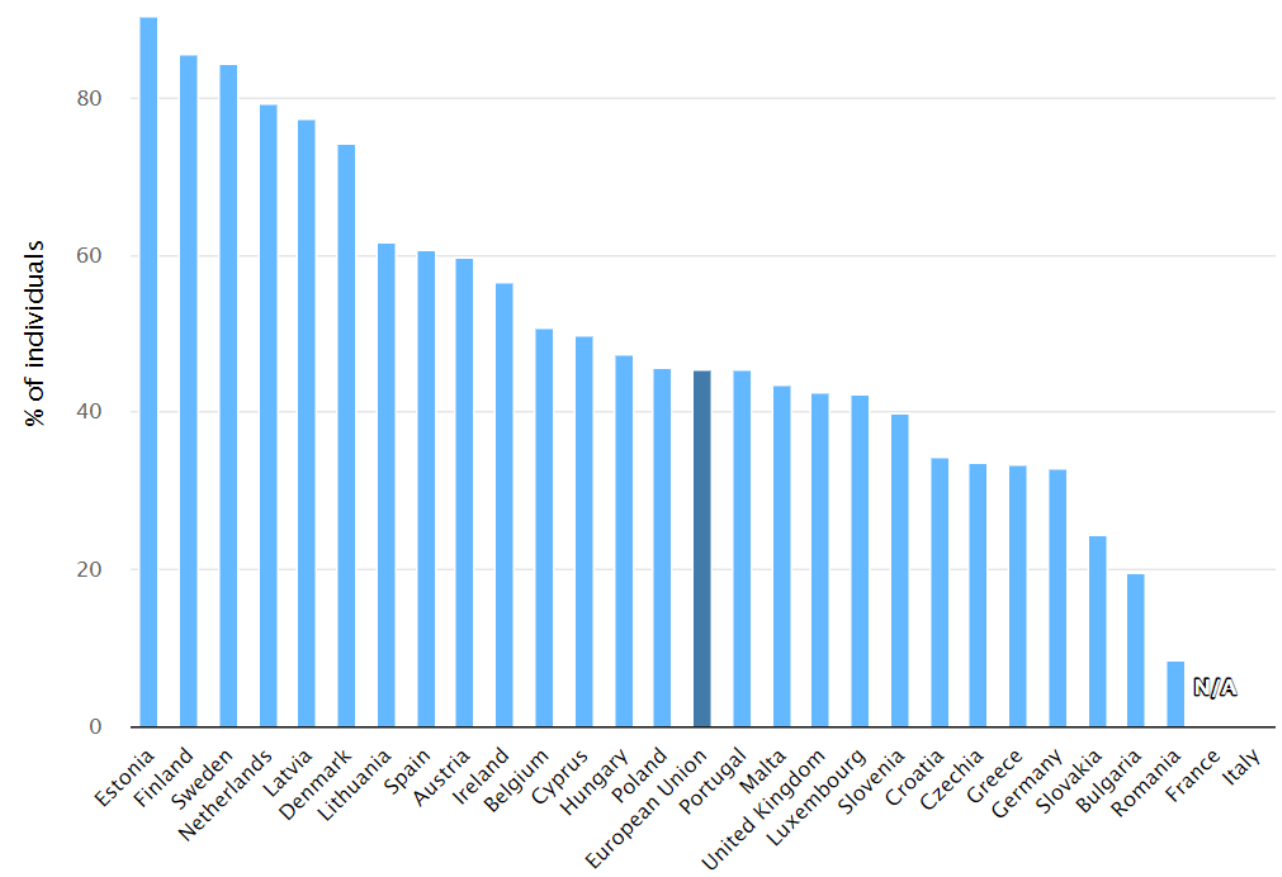

Chart 2: Individuals submitting completed forms to public authorities, over the internet

Chart 2 presents the percentage of individuals aged 25 to 54 who have submitted completed forms to public authorities via internet in the past 12 months. The top 3 countries are Estonia (90.3\%), Finland (85.4\%) and Sweden (84.4\%). The countries with the lowest percentages are Slovakia (24.4\%), Bulgaria (19.6\%) and Romania $(8.47 \%)$.

The poor performance registered by Romania, Bulgaria and Slovakia could be explained through the lack of digital public services, but also through the lack of user centricity or user friendliness of the existing platforms. Moreover, the lack of digital skills among population is another potential significant factor of influence that should be analyzed. 


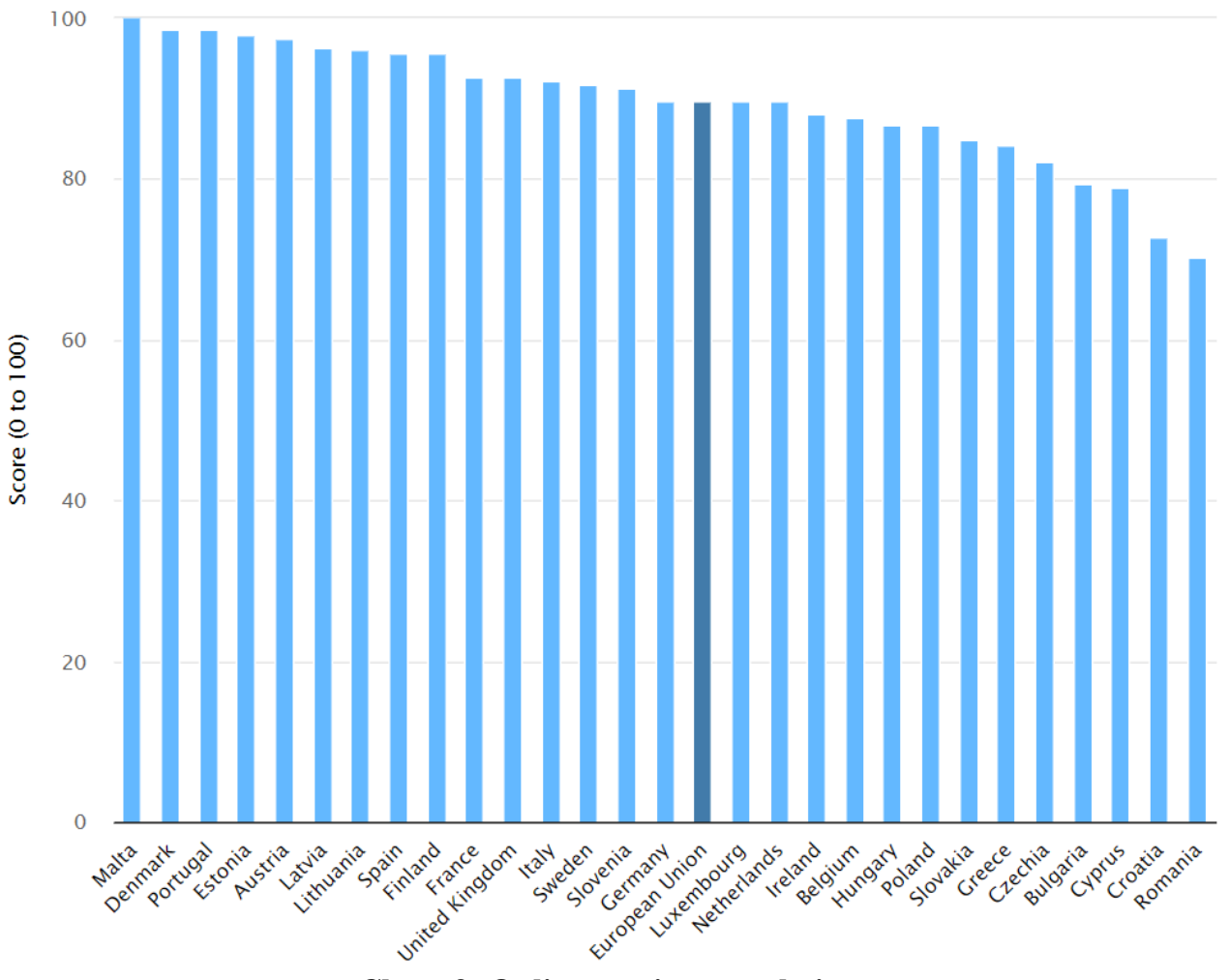

Chart 3: Online service completion

The online service completion score measures the percentage of the steps in a Public Service life event that can be completed online. Chart 3 shows that in Malta all the steps of all the public services that were analyzed, can be completed online. Other countries with the highest scores are Denmark and Portugal (98.6\%), Estonia (97.9\%) and Austria (97.4\%). The case of Austria is interesting because even if most of the steps in a Public Service life event can be completed online, only $49.9 \%$ of individuals aged 25 to 54 have submitted completed forms to public authorities, over the internet, in the last 12 months. We can suggest that the digital public services are either not user friendly or the digital skills of the population are not developed enough so the citizens can take advantage of digitalization.

The countries with the lowest scores in online service completion are Croatia (72.9\%) and Romania (70.3\%). 


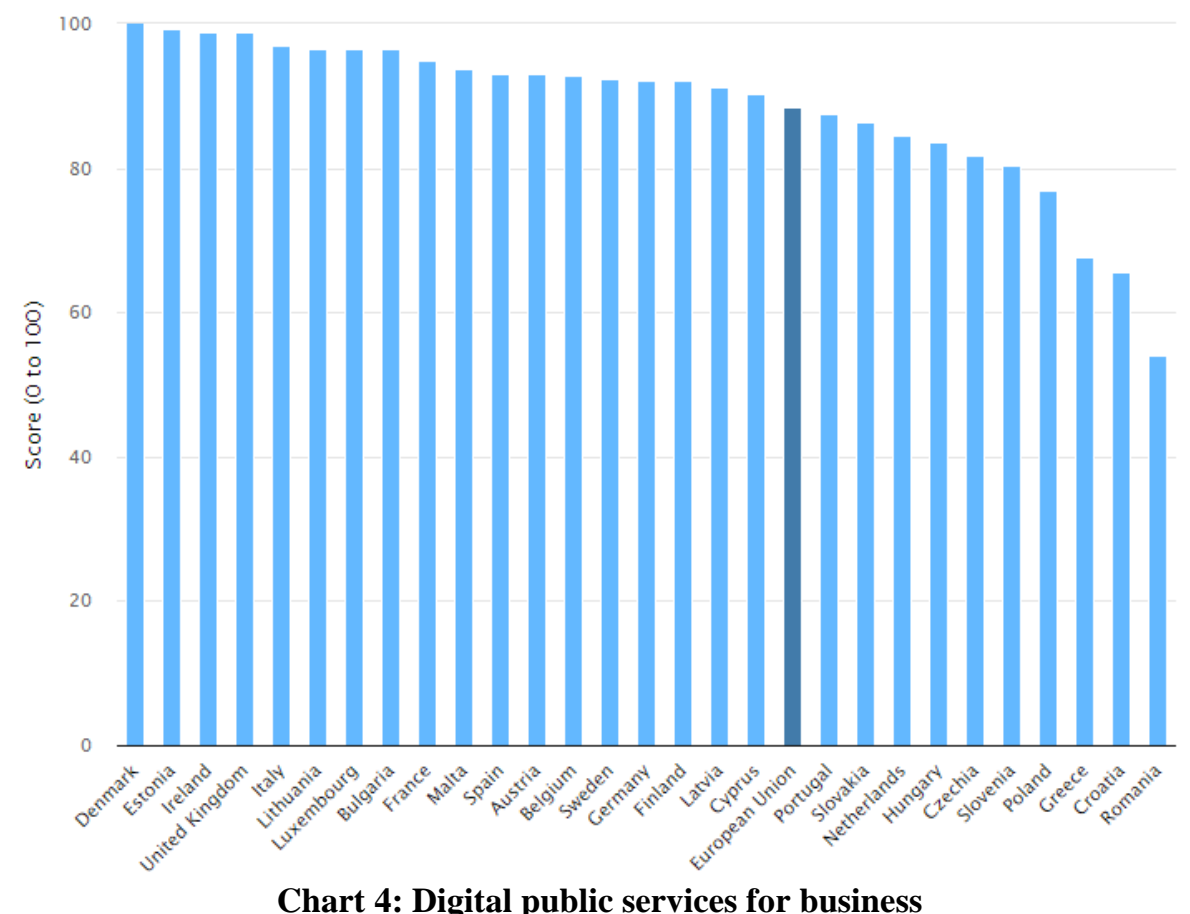

The digital public services for business indicator reflects the share of public services needed for starting a business and for conducting regular business operations that are available online for domestics as well as for foreign users.

As we can observe in Chart 4, the countries where individuals can use online platforms to access public services for starting and operating a business are Denmark, Estonia, Ireland, and UK. In these countries, almost all the steps necessary to set up and operate a business can be done online. The countries with the least online public services for entrepreneurs are Greece, Croatia, and Romania.

Taking the case of Romania, the low score in digital public services for business cannot be explained through the lack of digital skills in the general population. A more plausible explanation can lead us to public management issues. More data and further analysis can clarify the rout causes of the public management issues that led to the poot digital public services for businesses in Romania.

\section{Conclusions}

Any public administration can shift from traditional to digital delivery of public services as long as it understands the factors that may encourage and

108 Review of International Comparative Management

Volume 22, Issue 1, March 2021 
discourage citizens to use digital channels and as long as it designs interventions adapted to the factors of influence.

This paper provides a general analysis of the development of digital public services in the EU countries. Based on this analysis, public administration registering the lowest scores (i) can identify the best practices sources by looking at the countries with the highest scores, and (ii) can perform in depth research to identify the root causes of digital channels poor performance and improve them through custom-made interventions.

This paper shows that government from countries like Bulgaria, Croatia, Romania, and Greece may consider a systematic approach in analyzing the ambiguity and complexity of the digital public services delivery, relative to the cognitive effort and the digital skills of citizens. Also, these governments may consider developing a clear strategy for digitalization of public services, adopting one of the four main available interventions: parallel positioning, replacement positioning, supplemental positioning or integrated positioning.

\section{Acknowledgement}

This work was cofinanced from the European Social Fund through Operational Programme Human Capital 2014-2020, project number POCU/380/6/13/125015 "Development of entrepreneurial skills for doctoral students and postdoctoral researchers in the field of economic sciences."

\section{References}

1. Anthopoulos, L., Reddick, C., Giannakidou, I. and Mavridis, N., 2016. Why egovernment projects fail? An analysis of the Healthcare.gov website. Government Information Quarterly, 33(1), pp. 161-173.

2. Ebbers, W., Jansen, M. and van Deursen, A., 2016. Impact of the digital divide on egovernment: Expanding from channel choice to channel usage. Government Information Quarterly, 33(4), pp. 685-692.

3. Ebbers, W., Jansen, M., Pieterson, W. and van de Wijngaert, L., 2016. Facts and feelings: The role of rational and irrational factors in citizens' channel choices. Government Information Quarterly, 33(3), pp. 506-515.

4. Ebbers, W., Pieterson, W. and Noordman, H., 2008. Electronic government: Rethinking channel management strategies. Government Information Quarterly, 25(2), pp. 181-201.

5. Faulkner, N., Jorgensen, B. and Koufariotis, G., 2019. Can behavioural interventions increase citizens' use of e-government? Evidence from a quasi-experimental trial. Government Information Quarterly, 36(1), pp. 61-68.

6. Madsen, C.Ø., Kræmmergaard, P., 2016. Warm experts in the age of mandatory egovernment: Interaction among Danish single parents regarding online application for public benefits. Electronic Journal of E-Government, 14 (1), pp. 87-98

7. Pieterson, W., 2010. Citizens and Service Channels. International Journal of Electronic Government Research, 6(2), pp. 37-53. 